University of Zurich

Department of Economics

Working Paper Series

ISSN 1664-7041 (print)

ISSN 1664-705X (online)

Working Paper No. 49

\title{
Does it matter how happiness is measured? Evidence from a randomized controlled experiment
}

Raphael Studer

November 2011 


\title{
Does it matter how happiness is measured? Evidence from a randomized controlled experiment*
}

\author{
Raphael Studer \\ Department of Economics, University of Zurich
}

November 2011

\begin{abstract}
A continuous and a discrete rating scale were implemented for a single item happiness question in a representative survey. A randomized controlled experiment enables unique analyses on data quality and distributions, which suggest superiority of the continuous scale. Results raise doubts about earlier inferences drawn on correlates of happiness. So far only self-assessed discrete happiness data have been used for research into the determinants of happiness. However, distribution distortions were found for the numerically labeled discrete scale, especially for women. Through this discretization bias, the widely reported gender happiness inequality puzzle can be explained.
\end{abstract}

Keywords: happiness, subjective well-being, life satisfaction, likert scale, visual analogue scale, rating scales, gender inequalities, gender gap

JEL Codes: C81, I31

* Address for correspondence: University of Zurich, Department of Economics, Zürichbergstr. 14, CH8032 Zürich, Switzerland, శ +414463422 97, raphael.studer@econ.uzh.ch

I thank Rainer Winkelmann for useful comments and Maarten Streefkerk for assistance in data preparation. Funding from the Candoc Forschungskredit of the University of Zurich is gratefully acknowledged. This paper draws on data of the LISS panel of CentERdata. 


\section{Introduction}

Interest in the determinants of subjective well-being using survey data has burgeoned in recent years. Research is often based on happiness or life satisfaction data self-assessed by survey participants on a Likert scale (LS) (Likert, 1932). Even though the discrete rating scale is widely accepted, its properties, e.g. cardinality remain disputed (Kristoffersen, 2010). However, little has been done to find better alternatives. This study proposes a new continuous rating scale to measure individual happiness, the visual analogue scale (VAS). Results of the randomized controlled experiment identify stylized happiness facts as question design artifacts and strongly suggest the use of the VAS.

Many scholars have been interested in the design of the single item happiness question. It was Fordyce (1987) who proposed to assess happiness on a single item 11-point LS. But other rating scales have been tested (Diener, 1994). The effect of labels on LS scores was examined by Larsen et al. (1984). Differences among countries in interpretation of LS labels was studied using satisfaction vignettes (Kapteyn et al., 2010). Cummins (2003) investigated LS of variable discriminating power. Andrews and Crandall (1976) assessed data quality of 7-point LS, faces and ladder scales. However, all these rating scales remained discrete.

Van Praag and Ferrer-i-Carbonell (2004) noted that individuals likely perceive satisfaction as a continuous phenomenon bounded by the states of complete dissatisfaction and complete satisfaction. This statement seems to be widely accepted. For instance, ordered response models are used for LS happiness data and build on a continuous latent framework. But the necessary discretization of the underlying true happiness score into a LS score may lead to systematic transformation error. This stands in contrast to a continuous rating scale which may be perceived as a reference continuum of the latent happiness. Such a rating scale is the VAS.

The VAS (Hayes and Patterson, 1921) is simply a bounded line. Respondents assess their happiness by setting a marker on the VAS. The VAS has been extensively used in 
medical pain research (McCormack et al., 1988). With the development of computer based surveys, the accuracy and simplicity of implementation of the VAS has jumped up. A recent literature has compared LS and VAS in computer based experiments (Couper et al., 2006). But to my knowledge there have been only four happiness studies implementing the VAS (Matsubayashi et al., 1992; Saris et al., 1998; Bouazzaoui and Mullet, 2002; Hofmans and Theuns, 2008). Saris et al. (1998) did not declare how the "graphical line scale" was implemented and for which satisfaction domain it was used. The other three articles are small sample paper and pencil vignette studies, which do not have any counterfactual for the VAS scores, i.e. LS scores for the same individuals. This study proposes to close this gap.

The present paper is the first to implement the VAS for a single item happiness question in a representative survey. A unique randomized controlled experiment enables the identification of question design effects. Thanks to a large set of socioeconomic and sociodemographic variables heterogeneous mode effects can be identified and patterns and puzzles which occurred so far with LS data can be explained. The analyses conclude in favor of the VAS.

The article starts by presenting the survey and question design and assessing the quality of the experiment. Section 3 reviews the existing literature on comparison of single item happiness scales and provides among others estimates for reliability and validity measures. I conclude on equally reliable and valid data quality for both scales. Distributional analyses are presented in Section 4. The experiment shows the same people to be on average less happy when they use the VAS. Moreover, wider spread happiness scores appear for the VAS. Higher variance can be attributed to an increased likelihood of scoring closer to the extremes. In fact, the unexplained pattern of LS high frequency categories is due to too little discriminating power. Section 5 exploits the existence of two parallel happiness questions to investigate the impact of rating scales on correlates of happiness for a common set of respondents. All statistically significant determinants of happiness, except gender, 
are found to correlate stronger in absolute values with the VAS happiness scores than with the LS scores. The significant gender gap which is present when LS data is used vanishes with the use of VAS data. This study demonstrates that answer distortions of female respondents exist in the discrete numerically labeled measurement. This finding is in line with an earlier study (Conti and Pudney, 2011). Section 6 concludes.

\section{Survey Design}

The randomized controlled experiment used in this paper was implemented in the Longitudinal Internet Studies for the Social Sciences (LISS). The LISS panel was established by CentERdata based at Tilburg University in the Netherlands. 10'150 random addresses were drawn from a $10 \%$ sample of the Dutch population register. The oldest inhabitant was approached by a letter including 10 Euros. In case of non-response, the person was called or visited. 5176 households agreed to participate in the survey. Households without broadband internet connection or computer were provided with it. During the first survey year in 2007, the average monthly answer rate was $73 \%$ of all members of participating households (Scherpenzeel, 2009). Knoef and de Vos (2009) concluded on underrepresentation of elderly people and of some ethnicities. In 2009, a refreshment sample stratified by age, ethnicity and household types was successful in establishing representativeness of the LISS panel (de Vos, 2010).

A monthly e-mail invites participants to respond to the LISS panel. Monthly waves consist of three questionnaires. The Background Variable questionnaire needs only be updated if any changes in core socioeconomic or sociodemographic variables, such as income, education, age, civil status or household composition, occurred. A second questionnaire contains questions on one of the twelve Core Studies repeated every year, for instance on health or religion. A third questionnaire contains an Assembled Study, like the experiment analyzed in this paper. Survey respondents can choose which questionnaire they want to 
answer first.

The experiment was implemented during the survey months March and April 2011. The web link to the Assembled Study directed participants to a single item happiness question. Answers had to be given either on a LS or a VAS. Answer scales were randomly assigned in March at the moment people opened the questionnaire. In the subsequent month, the scales were changed or again randomly assigned if people had not answered during the March wave. In the best case scenario, every survey participant reported his or her happiness using the VAS and the LS. This crossover design has two advantages. First, the dependent sample increases power of test statistics. Second, any time effect affecting only subgroups of the sample is captured in both scales equally and does not distort the analysis.

The crossover experiment is summarized in figure 1. The samples consist of 5042 participants in wave 1 and 4795 participants in wave 2. The paired sample, individuals who responded in March and April 2011, includes 4274 observations. In May 2011, the month after the experiment took place, the LISS Core Study was dedicated to the personality questionnaire. This personality study gathers not only information on overall happiness on a LS ranging from 0 to 10 (11 points) but also on personality traits, like emotional stability or self esteem. 5230 individuals responded to the personality questionnaire in May, out of which 3770 individuals had already assessed their happiness in March and April. Data of the March and April waves will be uniquely used to quantify differences in means, variances (section 4) and correlates (section 5). For the assessment of data quality (section 3) data of the May wave will be employed additionally.

Screenshots of the two questions implemented in the experiment are presented in figure 2. The LS ranges from 0-9 (10 points). The VAS is a continuous line. It neither caries numbers nor does it show categories. However, for practical purposes, a scale unit has to be chosen for the VAS. In this application VAS scores were covertly measured from 0 to 99. Therefore, the VAS measurement has ten times more discriminating power than the LS 
measurement. In order to ensure comparability of the two rating scales, VAS scores were divided by 11 . Hence, in all analyses that follow, VAS and LS scores are comprised inside the closed interval from 0 to 9 . The design of both scales was the same: No questions were asked before the happiness question; the length of both scales was approximately equivalent; the VAS had no default marker to avoid artificial high frequency regions (Treiblmaier and Filzmoser, 2009); both scales were aligned horizontally, however, results should not differ to vertical scales (Funke et al., 2010; Paul-Dauphin et al., 1999); and the same anchor words were used for the LS and the VAS in order to avoid wording effects (Weng, 2004). I expect no hidden factors to drive any differences in responses between the two rating scales.

In order to examine the question design, participants answered 5 evaluation questions after participating in the experiment. Difficulty in answering, clearness of the question, degree of thought provocation, interest and joyfulness while responding were rated on a LS ranging from 1 (certainly not) to 5 (certainly yes). Figure 3 gives the distributions by scale types to all five evaluation questions. Distributions are very similar. A Kolmogorov Smirnov test rejects equality of distributions only for the question clearness. However, also for this question, densities in the five categories do not differ by more than 1 percentage point. Given this evidence, I conclude on absence of design artifacts causing response problems.

Two concerns about the experiment may still be raised. First, screen resolution may differ among survey participants. A lower resolution leads to a wider VAS or LS. Previous empirical findings however suggest no effect of varying length of the VAS (Keindler et al., 2003). Second, people can decide on the order of the three questionnaires each month on their own. Order of questionnaires have been shown to have important effects on answers (Schumann and Presser, 1981), however as will be shown it does not affect mean answers in this survey.

Table 1 and 2 examine the quality of the present experiment. First, table 1 evaluates whether the subsamples are truly random by comparing the means of ex-ante characteristics 
by scale types. Equality of means for any of the variables, except for out of labor force, working and foreigner cannot be rejected. However, the point estimates are very similar in magnitude for the two groups and differ only by 2-3 percentage points for these three variables. If randomization seems not complete in these three variables statistically, it is practically. The picture is similar for the April wave. Second, table 2 reports estimates of the parameters capturing a time or questionnaire order effect, if existent. The following model is estimated using the paired sample.

$$
\begin{aligned}
s_{i t} & =\beta_{0}+\beta_{1} \cdot \text { april }_{i t}+\beta_{2} \cdot \text { vas }_{i t}+\beta_{3} \cdot \text { april }_{i t} \cdot \text { vas }_{i t} \\
& +\beta_{4} \cdot \text { experiment } 2_{i t}^{\text {nd }}+\beta_{5} \cdot \text { vas }_{i t} \cdot \text { experiment } 2_{i t}^{\text {nd }}+\epsilon_{i t}
\end{aligned}
$$

The dependent variable $s_{i t}$ is the happiness score. The parameter $\beta_{1}$ estimates a potential time effect, which differs between scales through the interaction term $\beta_{3}$. The variable experiment $2_{i t}^{\text {nd }}$ takes the value 1 if during the 2 hours preceding the response of the happiness question, the Background Variable questionnaire was opened. This questionnaire order effect may also vary by scales through the interaction coefficient $\beta_{5}$. Table 2 shows that neither a time nor a questionnaire order effect exist for one or the other scale. It is concluded that the experiment was successful and that the findings presented below are only caused by different rating scales.

\section{$3 \quad$ Validity and reliability of the VAS}

A simple quality measurement of rating data is provided by the true score model (e.g., Saris and Gallhofer, 2007). Consider the observed score $s_{i}$ for individual $i$ being a noisy measure of the transformed score $t_{i}: s_{i j}=t_{i j}+\zeta_{i j}$. If the transformation for every rating scale $j$ is a linear function of the latent happiness $h_{i}: t_{i j}=v_{j} \cdot h_{i}+\eta_{i j}$, then substitution yields: $s_{i j}=v_{j} \cdot h_{i}+\epsilon_{i j}$. The three parameters of interest $v_{j}^{2}$ for all three rating scales at hand 
$(j=\{$ vas $, l s 10, l s 11\})$ are identified through the three correlations between the different $s_{i j}$ 's. In fact $\operatorname{corr}\left(s_{i, v a s} ; s_{i, l s 10}\right)=\frac{v_{l s 10} \cdot v_{v a s} \cdot \operatorname{Var}\left(h_{i}\right)}{\sqrt{\operatorname{Var}\left(s_{i, l s 10}\right) \cdot \operatorname{Var}\left(s_{i, v a s}\right)}}$, which reduces to $\operatorname{corr}\left(s_{i, v a s} ; s_{i, l s 10}\right)=$ $v_{l s 10} \cdot v_{v a s}$ if equality of variances is assumed. The lowest quality is found for the VAS (0.66) and equal quality for the two discrete measurements (0.71). However, this result is misleading. The estimates for $v_{j}^{2}$ are equal to $\frac{v_{j}^{2}}{\operatorname{Var}\left(s_{i}, j\right)}$, if only the variance of the latent happiness $\left(\operatorname{Var}\left(h_{i}\right)\right)$ is normalized to one. The next section will show that the variance of VAS scores is higher than the variances of the two LS scores. Therefore, VAS data quality in the true score model is smaller than those of the discrete rating scales, because VAS scores are wider spread. Better measurements for data quality have to be found.

Recent computer surveys experimentally implementing the LS and VAS used various methods to examine survey data. The item response time has been recorded. While Funke and Reips (forthcoming) found no difference, Cook et al. (2001) and Couper et al. (2006) have reporeted a longer response time for the VAS. Completion rates of questionnaires have been lower and questions were skipped more often if the VAS instead of the LS was used (Couper et al., 2006). Answers were modified nearly twice as often with the VAS (Funke and Reips, forthcoming). The data structure does not allow the analysis of all of these indicators.

In the experiment, randomization only took place when participants accessed the questionnaire. Therefore, item non-response cannot be assessed. Moreover, all participants finished the questionnaire and completion rates do not differ. This study finds higher average item response times for the VAS (16 seconds) than for the LS (10 seconds). However, this may be due to a difference in question design: the VAS question had one sentence more to read (figure 2). A higher fraction of survey participants was found to move back to adjust the happiness score for the VAS (2.3\%) than for the LS (1.4\%). This may simply indicate a lack of familiarity with the VAS as opposed to the LS.

Validity and reliability seem the most established measures to assess survey data quality. Validity quantifies the degree to which the rating scale is able to capture the true latent 
construct. A systematic error due to a nonconformity of a rating scale harms validity. Intuitively, the LS, requesting the categorization of a continuous feeling, may have lower validity than the VAS. Reliability is the extent to which the rating scale can reproduce its measurements. Low reliability is due to a random measurement error. The high sensitivity of the VAS may lead to lower reliability. Different methodologies have been established to investigate validity and reliability of rating scales.

A huge body of literature on reliability and validity of the LS and the VAS can be found in medical pain research. Validity has been tested by the administration of different intensities of heat (Price et al., 1994) or sound (Lara-Munoz et al., 2004) in a randomized order. Survey participants had to rate the level of pain on a LS or VAS. Flint et al. (2000) assessed reliability by letting people judge hunger feelings during two subsequent days while the authors controlled ingested energy. These three studies and all studies, which were reviewed, have either not been advising against the VAS or concluded in favor of it.

Happiness cannot be measured objectively, like heat or sound. The presence of validity in single item happiness responses has been evaluated through content or convergent validity (Diener, 1994). Content validity has been assessed by the correlation between individual happiness scores of different rating scales. Only marginal differences between the three implemented scales are observed. First, the VAS correlates with the Likert 11 and 10 point scales by 0.69 , whereas the two discrete measurements correlate by 0.72 (table 8). Magnitude of these point estimates is in line with earlier findings (e.g., Larsen et al., 1984). The positive correlations may indicate that all three measures assess the same latent construct, but cannot conclude which scale is best. Convergent validity in contrast ranks scales. In happiness research this has been done with the magnitudes of correlations between happiness scores and personality traits. This analysis therefore relies implicitly on the assumption of a valid scale of the external criterions, which are in most cases multiple item LS questions. Estimates of correlations between rating scales (columns) and the BIG V inventory (Goldberger, 1992) or the self-esteem scale (Rosenberg, 1965) are reported 
in table 4. These six trait variables were gathered in the personality study of the May wave. Personality traits are judged stable (e.g., Srivastava et al., 2003) though the time gap between the assessment of happiness (March, April, May) and personality traits (May) causes no problems. The magnitude of correlations are similar to earlier research (e.g., Larsen et al., 1984 or Abdel-Khalek, 2006). No pattern in lower or higher convergent validity for one scale is discovered. The VAS should be considered as a valid happiness scale, at least if the 10 or 11 point LS are judged as being it.

Reliability of single item happiness questions has been assessed through test-retest reliability. The test-retest method uses the same sample and the same measurement on two occasions. Larsen et al. (1984) and Krueger and Schkade (2008) have concluded on testretest reliability coefficients ranging from 0.4 to 0.6 for single item discrete measurements. The data structure of this study does not allow to present test-retest reliability coefficients.

Reliability can also be exploited using the experiment. It was shown that randomization was successful and that no time effect exists. Sample distributions in happiness scores should be equal between the March and April waves for each rating scale if the scales are reliable. In order to compare distributions among the two scales, the VAS score was split up in 10 equal intervals. Figure 4 shows the histograms for both waves for both scales. A huge agreement in the distribution in scores is observed. It could be judged marginally stronger for the VAS. The VAS is considered to be a reliable rating scale for happiness.

Survey happiness data assessed by a LS are widely accepted to be of good quality, i.e. to be valid and reliable. The existing methods to assess data quality suggest no exorbitant differences between the VAS and the LS. Moreover, the theoretical argument should be emphasized again. At least higher (theoretical) validity should be attributed to the VAS, because it overcomes idiosyncratic discretization and the line length acts as a reference continuum to represent perceived happiness. 


\section{The distribution of happiness scores}

Several computer based studies have reported equality in distributions between VAS and LS scores (e.g., Couper et al. 2006 or Funke and Reips, forthcoming). However, these studies have not asked people to assess subjective feelings, such as happiness. All of them have used objective judgments, as questions on clothing style or vignettes on behavior. A paper and pencil study on self reported individual coping reported lower mean values for the VAS (Flynn et al., 2006). Hence, distributions may be expected to differ.

Table 5 reports the first and second moments of both happiness scales, the LS and the VAS. t-tests on the equality of means and Levine's tests on the equality of variances for each wave and for the paired sample are presented. All three samples show the same picture: lower mean but wider spread happiness scores in the case of the VAS. All null hypotheses of equality of means and variances can be rejected.

The random assignment of response scales creates a control group (LS) of individuals that should have the same outcomes as what the treatment group (VAS) would have had if they had answered on the LS. The simple comparison in means therefore suggests that participants would have reporeted 0.45 points higher happiness on the LS than on the VAS. Due to the experimental set-up, controlling for a large set of socioeconomic and sociodemographic variables, such as age, household size, employment and marital status, gender, origin and education, does not change the point estimates but increases precision only. For a decomposition of the treatment effect in population subgroups readers are referred to the next section.

The difference in mean happiness may result from the comparison of a discrete measurement and a continuous measurement. For instance, VAS scores would be artificially lower, if a LS score of 9 maps an interval of latent happiness ranging from 8.5 to 9.4, but a VAS score of 9 represents a latent happiness of 9 only. In order to eliminate the influence of differences in perceptions, VAS scores were transformed into discrete scores and the mean comparison was repeated. To discretize the VAS, the line was divided into ten equally 
spaced intervals. The intervals were assigned the LS scores 0 to 9 in ascending order from left to right. The first column of table 6 shows once more the first and second moments for the LS. Means and variances for discrete VAS scores are presented in the second column. The difference in means suggests that participants would have been around 0.25 points happier on the LS than on the VAS. The treatment effect is lower compared to the previous analysis, but stays significant, negative and large. Hence, people are on average happier on the LS than on the VAS.

The second finding reported in table 5 is an increase in variances of 0.8 points, when moving from the LS to the VAS. Wider spread happiness scores contain more information. However, higher variance in the VAS scores may simply be due to the high sensitivity of the scale. For instance, people would like to cross the equivalent of a 7 but crossed 6.8 instead. The thesis of inexactness can be easily tested. First, if it holds true, than the discretized VAS should have lower variance. Table 6 shows the contrary: the variance increases by another 0.5 points. Second, distributions of happiness scores give more evidence that not the higher sensitivity is the trigger of higher variances. Figure 6 plots a histogram for the LS scores and a kernel density estimate for the VAS scores of the March wave. For the latter the Epanechnikov kernel and the bandwidth that minimizes the mean integrated squared error (bandwidth $=0.23$ ) are used. Two patterns can be found. First, response densities are lower in the categories 7 and 8. Second, people are more likely to score close to the two boundaries. Higher variance is in part explained by a shift in answers towards the extremes.

The differences in distributions can be quantified. Three variables indicating the location of the scores on the discretized scales are generated. All indicator variables are equal to 0 except that the first is 1 if the individual answered a 7 or 8 , the second is 1 if the score was equal to 1, 2 or 3 and the last is 1 if a 9 was observed. For each of these indicator variables a linear probability model is estimated using the paired sample. A large set of socioeconomic and demographic variables as well as a wave dummy and dummies indicating 
the questionnaire and question order are included in the regression. Table 7 reports the estimates of the parameter of interest, i.e. the average effect of the VAS on the probability of scoring in one of these intervals. All effects were found to be large and significant. The probability that a participant scores a 7 or 8 is reduced by over 21 percentage points if the VAS was used. This effect can be divided in the two effects prevailing at the extremes. In the case of the VAS the probability of a 9 is more than 8 percentage points higher and the probability of scoring either a 1,2 or 3 is more than 2 percentage points higher. The shifts in distributions are substantial.

The higher variance in VAS scores due to more extreme answers reveals the LS high frequency categories as a scale artifact. An earlier international comparison concluded on Dutch people being more likely to avoid extreme LS values (Kapteyn et al., 2007). But the present results show that even Dutch respondents are willing to score closer to the boundary, but not at the boundary itself. A continuous measurement with infinitely fine categories enables respondents to approach the boundaries and thus overcomes answer distortions caused by a too insensitive answer scale.

\section{The correlates of happiness}

Research into the determinants of subjective well-being has burgeoned in recent years, and valuable insights have been obtained (e.g., Kahneman and Krueger, 2006). Scholars have been interested in the effects of schooling (Orepolus, 2003), income (Easterlin, 1995), unemployment (Winkelmann and Winkelmann, 1998) or age (Stone et al., 2010). Many findings have been replicated for different countries and have been judged as robust (Frey and Stutzer, 2002). All these studies use discrete happiness data. Therefore, the question arises: How much are these findings affected by the specificities of the LS?

The paired sample consists of the same set of respondents assessing their happiness either on the VAS or the LS. From March to April, no individual reported changes in 
core socioeconomic or sociodemographic variables. Regressions for both scales of happiness scores on a set of socioeconomic and sociodemographic variables should estimate the same effects. Any changes in correlates when moving from one to the other scale can be attributed to the scale design.

Table 8 shows estimates by scale types of a linear regression modeling happiness scores as dependent variable. Results for the LS are in line with the research literature (e.g. Kahneman and Krueger, 2006 or Frey and Stutzer, 2002). Happiness is found to be Ushaped in age, foreigners and unemployed are less and women more happy. Marriage and house ownership, the latter may be interpreted as a proxy for savings, have a positive effect on happiness. However, these findings do not carry over to the VAS regression.

Comparison of the LS correlation coefficients with those of the VAS sample reveals some striking findings. Signs of statistically significant explanatory variables stay the same. But the equality of coefficients is rejected by a Chow test ( $\mathrm{p}$-value $=0.012$ ). Except for the male dummy, effects of statistically significant variables are in absolute values stronger in the VAS regression. These findings need some investigation.

Happiness data is generally criticized to contain a mix of short and long term circumstances. If the explanatory variables in the regression are judged as indicators for long term factors, higher coefficients of statistically significant variables raise the question whether the VAS scores contain more information on long term factors causing well-being. Due to the wider spread VAS scores the VAS regression model has to explain more variance. However, the $R^{2}$ remain the same for both regressions (0.09). This indicates that the model explains more absolute variance, but that in both regressions the same relative amount of error variance is present. Both scales seem to capture to the same degree short and long term factors causing happiness.

The most powerful finding reported in table 8 is the change in statistical significance of the gender variable. In the LS sample men are found to be 0.162 points less happy than women. This is a huge effect. For instance, a male with an average income must be 
compensated with an income increase of $17 \%$ to make him at least as well off as his female counterpart. When the VAS sample is used, the happiness gender inequality vanishes.

The disappearance of the gender gap indicates that subgroups of the population may be influenced to different degrees by rating scale design. In order to identify heterogeneous effects, the difference in happiness scores is computed for every individual. The LS score is subtracted from the VAS score and the difference regressed on the same set of explanatory variables as in the regression analyses. Table 9 reports the estimates of this regression. The constant indicates that the reference group scored on average lower on the VAS. Three variables drive participants to score relatively higher on the VAS than the reference group: Marriage, houseownership and most important being of male sex. Hence, question design affects subgroups of the population differently. Gender is found to play a major role in perception of answer scales.

To see what drives the heterogeneous responses, three indicator variables were computed. The first takes the value 1 if the difference in happiness scores between the LS and the continuous VAS scores is $<-1$, the second if it is $>1$ and the last if it is in between -1 and 1 . For each of these dependent variables a linear probability model was estimated. Estimates for the average effect of gender are presented in table 10. Women are more than 6 percentage points likelier to have a difference in scores smaller than -1 . Men have a 5 percentage points higher probability than women of having minimal changes between the VAS and the LS. This finding suggests that women are the trigger. If everybody scores on average lower on the VAS, women's happiness scores fall even more. Women overrate their happiness as soon as a numbered scale is used. Therefore, doubts araise concerning the reliability of inferences that have been drawn earlier on the gender gap.

If a gender gap existed, it would be an important finding as it may reflect gender inequalities present in a society. It has been a often disputed topic in the literature and is a veritable puzzle. Some studies have found female to be happier (e.g., Gerdtham and Johannesson, 2001; Lalive and Stutzer, 2010). Others concluded on equally happy gender 
(e.g., Fujita et al., 1994) or on a declining gender inequality over the last decades (Stevenson and Wolfers, 2009). In an early attempt, Wood et al. (1989) reviewed nearly 100 studies and concluded that a gender gap was only found in representative surveys when single item happiness questions were used. But may a gender gap not be a consequence of rating scale design?

Support for the hypothesis that a gender gap in happiness results from numerically labeled LS can be found. First, the above mentioned papers concluding on a gender gap have effectively been using LS type data. Second, the May wave of the data provides a second discrete measurement of happiness. The regression reported in table 8 was repeated using the LS data with 11 categories ranging from 0 to 10 . Estimates, not reported in this paper, again identified women to be 0.11 points happier than men on average. Discrete single item happiness questions seem to be the reason for a difference in happiness between women and men.

In order to confirm our results more studies on rating scale design for happiness measurement are needed. However, unless something else is demonstrated, scholars using LS type data should be careful in interpreting gender happiness differences.

\section{Conclusion}

Most of the studies interested in determinants of happiness have used discrete satisfaction scores as dependent variables. This may be because they are widely available in crossectional or panel surveys. This paper suggests to move away from the discrete Likert scale. The visual analogue scale, a continuous measurement, was implemented in the Dutch Longitudinal Internet Study for Social Sciences. The present study is the first to exploit a randomized controlled experiment to compare a single item happiness question assessed either on a LS or on a VAS. Results are promising. First, survey participants did not manifest problems in using the VAS. Second, no differences in data quality were found between 
the VAS and LS. Third, lower mean and wider spread happiness scores for the VAS were detected. Higher variance is not due to the high sensibility of the VAS but to the increased likelihood of participants of scoring close to the boundaries. This finding explains the high frequency LS categories 7 and 8 as a result of too little discriminating power. Fourth, gender specific question design effects were found. Whereas women reported on average 0.56 points higher happiness on the numerically labeled LS than on the VAS, men's mean score was lowered by 0.41 points only. This gender specific response behavior identifies the gender happiness inequality, i.e. women being on average happier than men, which is a robust empirical finding, as an artifact of the LS type data.

Analyses suggest that the VAS is preferable to the LS. On one hand, the VAS can be theoretically interpreted as a reference continuum for the latent continuous happiness. On the other hand, the VAS overcomes empirical distribution distortions of numerically labeled LS.

\section{References}

Abdel-Khalek, A.M., 2006, "Measuring Happiness with a Single-Item Scale", Social Behavior and Personality, Vol. 34, No.2, 139-150

Andrews F.M. and R.Crandall, 1976, "The Validity of Measures of Self-Reported WellBeing", Social Indicators Research, Vol. 3, 1-19

Bouazzaoui, A.B. and E. Mullet, 2006, "Employment and Family as Determinants of anticipated Life Satisfaction: Contrasting European and Maghrebi People's Viewpoints", Journal of Happiness Studies Vol.6, 161-185

Conti, G. and S. Pudney, 2011, "Survey Design and the Analysis of Satisfaction", The Review of Economics and Statistics, Vol. 93, No. 3, 1087-1093

Cook, C., F. Heath and R.L. Thompson, 2001, "Score reliability in web- or Internet-based surveys: Unnumbered graphic rating scales versus Likert-type scales", Educational and Psychological Measurement, 61, 697-706

Couper, M.P., R. Tourangeau, F. G. Conrad and E. Singer, 2006, "Evaluating the Effectiveness of Visual Analog Scales : A Web Experiment", Social Science Computer Review, Vol. 24, No. 227 
Cummins, R.A., 2001, "Normative Life Satisfaction: Measurement Issues and a Homeostatic Model", Social Indicators Research, Vol.64

de Vos, K., 2010, "Representativeness of the LISS-panel 2008, 2009, 2010", http://www.lissdata.nl, last consultation 14.10.2011

Diener, E., 1994, "Assessing Subjective Well-Being: Progress and Opportunities", Social Indicators Research, Vol. 31, No. 2, 103

Easterlin, R., 1995, "Will Raising the Incomes of All Increase the Happiness of All?", Journal of Economic Behavior and Organisation, Vol. 27, No. 1, 35-48

Flint, A., A. Raben, J.E. Blundell and A. Astrup, 2000, "Reproducibility, power and validity of visual analogue scales in assessment of appetite sensations in single test meal studies", International Journal of Obesity, Vol24, 38-48

Flynn, D., P. van Schaik and A. van Wersch, 2004, "A Comparison of Multi-Item Likert and Visual Analogue Scales for the Assessment of Transactionally Defined Coping Function", European Journal of Psychological Assessment, Vol. 20, No. 1, 49-58

Fordyce, M.W., 1987, "A Review of Research on the Happiness Measures: A Sixty Second Index of Happiness and Mental Health", Alex C. Michalos (ed), Citation Classics from Social Indicators Research,2005, 373-399

Frey, B.S. and A. Stutzer, 2002, "The Economics of Happiness", World Economics, Vol. 3, No. 1

Funke, F., U.-D. Reips and R. K. Thomas, 2010, "Sliders for the Smart: Type of Rating Scale on the Web Interacts With Educational Level", Social Science Computer Review

Funke, F., U.-D. Reips, forthcoming, "Why Semantic Differentials in Web-Based Research Should be Made From Visual Analogue Scales and Not From 5-Point Scales", Field Methods, Vol 24, No. 3

Fujita, F., E. Diener and E. Sandvik, 1991, "Gender Differences in Negative Affect and Well-Being: The Case for Emotional Intensity", Journal of Personality and Social Psychology, Vol.6, No. 3, 427-434

Gerdthama, U.G. and M. Johannesson, 2001, "The relationship between happiness, health, and socioeconomic factors: results based on Swedish microdata", Journal of SocioEconomics, Vol. 30, 553-557

Goldberger, L.R., 1992, "The Development of Markers for the Big-Five Factor Structure", Psychological Assessment, Vol4, No.3, 26-42

Hayes, M. H. S. and D. G. Patterson, 1921, "Experimental development of the graphic rating method", Psychological Bulletin, Vol. 18, 98-99

Hofmans, J. and P. Theuns, "On the linearity of predefined and self-anchoring Visual Analogue Scales", British Journal of Mathematical and Statistical Psychology, Vol. $61,401-413$ 
Kahneman, D. and A.B. Krueger, 2006, "Developments in the Measurement of Subjective Well-Being", Journal of Economic Perspectives, Vol. 20, No. 1, 3-24

Kapteyn, A., J.P. Smith and A. van Soest, 2007, "Vignettes and self-reports of work disability in the U.S. and the Netherlands", American Economic Review, Vol. 97, 461-473

Kapteyn, A., J.P. Smith and A. van Soest, 2010, "Life Satisfaction" in: E. Diener, J.F. Helliwell, D. Kahneman (eds), International Differences in Well-Being, Oxford University Press, 70-104

Knoef M. and K. de Vos, 2009, "The representativeness of LISS", an online probability panel http://www.lissdata.nl, last consultation 14.10.2011

Kreindler, D., A. Levitta, N. Woolridge, and C.J. Lumsdenc, 2003, "Portable moodmapping: the validity and reliability of analog scale displays for mood assessment via hand-held computer", Psychiatry Research, Vol.120, 165-177

Kristoffersen, I., 2010, "The Metrics of Subjective Wellbeing: Cardinality, Neutrality and Additivity", The Economic Record, Vol. 86, No. 272, 98-123

Krueger, B. and D.A. Schkade, "The Reliability of Subjective Well-Being Measures", Journal of Public Economics, Vol. 92, 1833-1845

Lalive R. and A. Stutzer, 2010, "Approval of equal rights and gender differences in wellbeing", Journal of Population Economics, Vol. 23, 933-962

Lara-Munoz, C., S.P. de Leon, A. R. Feinstein, A. Puentee and C. K. Wells, 2004, "Comparison of Three Rating Scales for Measuring Subjective Phenomena in Clinical Research", Archives of Medical Research, Vol. 35, 43-48

Larsen, R.J., E. Diener, R.A. Emmons, 1985, "An Evaluation of Subjective Well-Being Measures",Social Indicators Research, Vol. 17, No. 1

Likert, R., 1932, "A Technique for the Measurement of Attitudes", Archives of Psychology, Vol. 140, 1-55

Matsubayashi K., S. Kimura,T. Iwasaki, K. Okumiya, T. Hamada,M. Fujisawa, K. Takeuchi,T. Kawamoto and T. Ozawa, 1992, "Application of visual analogue scale of happiness to elderly Himalayan highlanders", Nippon Ronen Igakkai Zasshi, Vol.29, No.(11), 823-828

McCormack, H.M., D.J.L. Horne and S. Sheater, 1988, "Clinical Applications of Visual Analogue Scales: A critical Review", Psychological Medicine, Vol. 18, 1007-1019

Oreopoulos, P., 2003, "Do Dropouts Drop Out Too Soon? Evidence from Changes in School-Leaving Laws" Mimeo, University of Toronto, March

Paul-Dauphin, A., F. Guillemin, J.M. Virion and S. Briancon, 1999, "Bias and Precision in Visual Analogue Scales: A Randomized Controlled Trial", American Journal of Epidemiology, Vol. 150, No. 10 
Price, D.D., F. M. Bush, S. Long and S. W. Harkins, 1994, "A comparison of pain measurement characteristics of mechanical visual analogue and simple numerical rating scales", Pain, 56, 217-226

Rosenberg, M., 1965, "Society and the adolescent self-image", Princeton University Press, New Jersey

Saris W.E. and I.N. Gallhofer, 2007, "Design, Evaluation, and Analysis of Questionnaires for Survey Research", Hoboken, New Jersey

Scherpenzeel, A., "Start of the LISS panel: Sample and recruitment of a probability-based Internet panel", http://www.lissdata.nl, last consultation 14.10.2011

Schuman, H. and S. Presser, 1981, "Questions and Answers in Attitudes Surveys Experiments in Question Forms Wording and Context", New York, Academic Press

Srivastava, S., O.P. John, S.D. Gosling, and J. Potter, 2003, "Development of personality in early and middle adulthood: Set like plaster or persistent change?", Journal of Personality and Social Psychology, Vol. 84, 1041-1053

Stevenson, B. and J. Wolfers, 2009, "The Paradox of Declining Female Happiness", NBER Working Paper 14969

Stone, A.A., J.E. Schwartz, J.E. Brodericka and A. Deaton, 2010, "A Snapshot of the Age Distribution of Psychological Well-being in the United States", PNAS Paper

Treiblmaier, H., P. Filzmoser, 2009, "Benefits from using continuous rating scales in online survey research" Technische Universitt Wien, Forschungsbericht

van Praag, B.M.S.and A. Ferrer-i-carbonell, 2004, Happiness Quantified: A Satisfaction Calculus Approach, Oxford University Press, New York

Weng, L.-J., 2004, "Impact of The Number of Response Categories and Anchor Labels on Coefficient Alpha and Test-Retest Reliability", Educational and Psychological Measurement, Vol. 64, 956-972

Winkelmann, L. and R. Winkelmann, 1998, "Why Are the Unemployed So Unhappy? Evidence from Panel Data", Economica, Vol. 65, No. 257, 1-15

Wood, W., N. Rhodes and M. Whelan, 1989, "Sex Differences in Positive Well-Being: A Consideration of Emotional Style and Marital Status", Psychological Bulletin, Vol. 106, No. 2, 249-264 


\section{Tables}

Table 1: Test for Randomization - March Sample

\begin{tabular}{|c|c|c|c|c|c|}
\hline & \multicolumn{2}{|c|}{ LS } & \multicolumn{2}{|c|}{ VAS } & \multirow{2}{*}{$\begin{array}{l}\text { Mean Equality } \\
\text { T-Test (P-Value) }\end{array}$} \\
\hline & Obs & Mean & Obs & Mean & \\
\hline Proportion male & 2537 & 0.46 & 2505 & 0.47 & 0.54 \\
\hline Net monthly income (EUR) & 2423 & 1526.98 & 2359 & 1499.51 & 0.81 \\
\hline Age & 2537 & 49.71 & 2505 & 49.96 & 0.61 \\
\hline Number of hh-members & 2537 & 2.62 & 2505 & 2.62 & 0.93 \\
\hline Number of hh-kids & 2537 & 0.85 & 2505 & 0.84 & 0.85 \\
\hline Proportion houseowner & 2537 & 0.73 & 2505 & 0.72 & 0.66 \\
\hline Proportion out of laborforce & 2537 & 0.36 & 2505 & 0.38 & 0.05 \\
\hline Proportion unemployed & 2537 & 0.03 & 2505 & 0.03 & 0.49 \\
\hline Proportion working & 2537 & 0.53 & 2505 & 0.50 & 0.08 \\
\hline Proportion high-educated & 2537 & 0.44 & 2505 & 0.44 & 0.80 \\
\hline Proportion low-educated & 2537 & 0.45 & 2505 & 0.44 & 0.60 \\
\hline Proportion married & 2537 & 0.57 & 2505 & 0.58 & 0.33 \\
\hline Proportion separated & 2537 & 0.09 & 2505 & 0.09 & 0.81 \\
\hline Proportion foreigner & 2483 & 0.13 & 2439 & 0.11 & 0.01 \\
\hline
\end{tabular}

Table 2: Regression of Happiness on VAS, Wave and Questionnaire Order Dummies with Interactions

\begin{tabular}{lcc} 
& Coefficient & Standard Error \\
\hline April & -0.02 & 0.04 \\
VAS·April & 0.01 & 0.08 \\
Experiment $2^{\text {nd }}$ & -0.05 & 0.04 \\
VAS·Experiment $2^{\text {nd }}$ & -0.03 & 0.06 \\
VAS & $-0.44^{* * *}$ & 0.06 \\
\hline
\end{tabular}

Paired sample: $N=8548$

Standard errors clustered by individual

*** significant at the 1 percent level, ${ }^{* *}$ at the 5 percent level, $*$ at the 10 percent level

Experiment $2^{n d}$ equals 1 if during the 2 hours preceding the lifesatisfaciton questionnaire the background variable questionnaire was answered.

Table 3: Pearson's Correlation between Rating Scales

\begin{tabular}{lccc} 
& $\begin{array}{c}\text { VAS } \\
\text { March/April }\end{array}$ & $\begin{array}{c}\text { LS } \\
\text { March/April }\end{array}$ & $\begin{array}{c}\text { LS } \\
\text { May }\end{array}$ \\
\hline VAS March/April & 1 & 0.69 & 0.69 \\
LS March/April & & 1 & 0.72 \\
LS May & & 1 \\
\hline $\begin{array}{l}N=3987 \\
\text { The L of the March and April waves ranged from 0 to 9, whereas the LS of the May } \\
\text { wave from 0 to 10. }\end{array}$
\end{tabular}


Table 4: Convergent Validity of Rating Scales

VAS LS LS

March/April March/April May

\begin{tabular}{llll} 
Extraversion & 0.19 & 0.21 & 0.22 \\
Agreeableness & 0.08 & 0.09 & 0.11 \\
Consciousness & 0.17 & 0.16 & 0.19 \\
Emotional stability & 0.43 & 0.40 & 0.43 \\
Openness to experience & 0.03 & 0.04 & 0.05 \\
Self-esteem & 0.41 & 0.40 & 0.43 \\
\hline
\end{tabular}

$N=3987$ f from 0 to 10 .

Table 5: Mean and Variance of Happiness Scores

LS VAS Mean Equality Variance Equality T-Test Levine's Test

\begin{tabular}{lcccc}
\hline March wave & 7.16 & 6.70 & 0.00 & \\
& $(1.22)$ & $(1.53)$ & & 0.00 \\
April wave & 7.14 & 6.70 & 0.00 & 0.00 \\
& $(1.18)$ & $(1.49)$ & & \\
Paired sample & 7.16 & 6.71 & 0.00 & 0.00 \\
& $(1.19)$ & $(1.50)$ & & \\
\hline
\end{tabular}

Standard deviations in parentheses

P-values reported for tests

Table 6: Mean and Variance of Discrete Happiness Scores

LS Discretized VAS Mean Equality Variance Equality T-Test Levine's Test

\begin{tabular}{lcccc}
\hline March wave & 7.16 & 6.92 & 0.00 & \\
& $(1.22)$ & $(1.69)$ & 0.00 \\
April wave & 7.14 & 6.91 & 0.00 & 0.00 \\
& $(1.18)$ & $(1.65)$ & & \\
Paired sample & 7.16 & 6.91 & 0.00 & 0.00 \\
& $(1.19)$ & $(1.66)$ & & \\
\hline
\end{tabular}

To discretize the VAS, scores were grouped into 10 equally spaced intervals.

Standard deviations in parentheses
P-values reported for tests 
Table 7: Differences in Happiness Distributions among Scales Participant scored

\begin{tabular}{lccc} 
& not a 7 or 8 & one of 4 lowest scores & highest score \\
\hline VAS Dummy & $0.216^{* * *}$ & $0.026^{* * *}$ & $0.082^{* * *}$ \\
& $(0.009)$ & $(0.003)$ & $(0.006)$ \\
\hline Paired sample: $N=7114$ & & \\
Average probability effects estimated by linear probability models \\
To discretize the VAS, scores were grouped in 10 equally spaced intervals. \\
In parentheses standard errors clustered by individual \\
$* * *$ significant at the 1 percent level, ** at the 5 percent level, * at the 10 percent level \\
Other control variables: order of question type, order of questionnaires, gender, lnetinc, age, \\
age2, number of person in hh, number of kids in hh, cohabitation with partner, houseownership, \\
employment- and marital status, education level, origin.
\end{tabular}

Table 8: Regression of Happiness on Characteristics for each Scale

\begin{tabular}{|c|c|c|c|c|}
\hline & \multicolumn{2}{|l|}{$\mathrm{LS}$} & \multicolumn{2}{|c|}{ VAS } \\
\hline & Coefficient & S.E. & Coefficient & S.E. \\
\hline Male & $-0.162^{* * *}$ & 0.042 & -0.012 & 0.054 \\
\hline Log of Monthly Net Income (EUR) & $0.131^{* * *}$ & 0.035 & $0.157^{* * *}$ & 0.045 \\
\hline Age & $-0.042^{* * *}$ & 0.008 & $-0.045^{* * *}$ & 0.010 \\
\hline $\mathrm{Age}^{2} \cdot 10^{-2}$ & $0.044^{* * *}$ & 0.008 & $0.045^{* * *}$ & 0.010 \\
\hline Number of hh-members & -0.028 & 0.101 & -0.163 & 0.128 \\
\hline Number of hh-kids & -0.014 & 0.103 & 0.131 & 0.131 \\
\hline Cohabiting & $0.286^{* * *}$ & 0.111 & $0.397^{* * *}$ & 0.140 \\
\hline Houseownership & $0.267^{* * *}$ & 0.047 & $0.362^{* * *}$ & 0.059 \\
\hline In workforce & $0.113^{* *}$ & 0.055 & $0.163^{* *}$ & 0.070 \\
\hline Unemployment & -0.138 & 0.121 & 0.021 & 0.153 \\
\hline Secondary Education & -0.004 & 0.072 & -0.013 & 0.091 \\
\hline Vocational Education & -0.026 & 0.074 & -0.091 & 0.094 \\
\hline Married & $0.338^{* * *}$ & 0.064 & $0.468^{* * *}$ & 0.081 \\
\hline Separated & -0.053 & 0.074 & -0.134 & 0.093 \\
\hline Foreigner & $-0.167^{* * *}$ & 0.061 & $-0.180 * *$ & 0.077 \\
\hline Experiment $2^{\text {nd }}$ & 0.008 & 0.046 & -0.073 & 0.058 \\
\hline April dummy & -0.028 & 0.038 & 0.010 & 0.048 \\
\hline Constant & 6.651 & 0.298 & 6.074 & 0.379 \\
\hline
\end{tabular}

$N_{l s}=N_{v a s}=3557$,
$* * *$ significant at the 1 percent level, $* *$ at the 5 percent level, * at the 10 percent level 
Table 9: Regression of Happiness Difference on Characteristics

\begin{tabular}{|c|c|c|}
\hline & Coefficients & S.E. \\
\hline Male & $0.148^{* * *}$ & $(0.041)$ \\
\hline Log of Monthly Net Income (EUR) & 0.026 & $(0.030)$ \\
\hline Age & -0.003 & $(0.008)$ \\
\hline $\mathrm{Age}^{2} \cdot 10^{-4}$ & -0.148 & $(0.834)$ \\
\hline Number of hh-members & -0.134 & $(0.105)$ \\
\hline Number of hh-kids & 0.144 & $(0.106)$ \\
\hline Cohabiting & 0.111 & $(0.116)$ \\
\hline Houseownership & $0.095^{* *}$ & $(0.047)$ \\
\hline In workforce & -0.050 & $(0.056)$ \\
\hline Unemployment & 0.158 & $(0.140)$ \\
\hline Secondary Education & -0.011 & $(0.072)$ \\
\hline Vocational Education & -0.066 & $(0.073)$ \\
\hline Married & $0.132^{* *}$ & $(0.064)$ \\
\hline Separated & -0.079 & $(0.081)$ \\
\hline Foreigner & -0.012 & $(0.065)$ \\
\hline Experiment $2^{n d}$ March & 0.005 & $(0.044)$ \\
\hline Experiment $2^{\text {nd }}$ April & -0.062 & $(0.036)$ \\
\hline VAS·March & -0.021 & (0.036) \\
\hline Constant & -0.560 & $(0.285)$ \\
\hline
\end{tabular}

Table 10: Strength of Happiness Difference for Gender

Participant had a happiness score difference smaller than -1 inbetween -1 and 1 larger than 1

\begin{tabular}{llcc}
\hline Male & $-0.063^{* * *}$ & $0.049^{* * *}$ & $0.014^{*}$ \\
& $(0.016)$ & $(0.017)$ & $(0.008)$ \\
\hline
\end{tabular}

Paired sample: $N=7114$

Average probability effects estimated by linear probability models

In parentheses standard errors clustered by individual

*** significant at the 1 percent level, $* *$ at the 5 percent level, $*$ at the 10 percent level

Other control variables: order of question type, order of questionnaires, gender, lnetinc,

age, age ${ }^{2}$, number of person in hh, number of kids in hh, cohabitation with partner,

houseownership, employment- and marital status, education level, origin. 


\section{Graphs}

Figure 1: Data Structure: Stocks and Flows

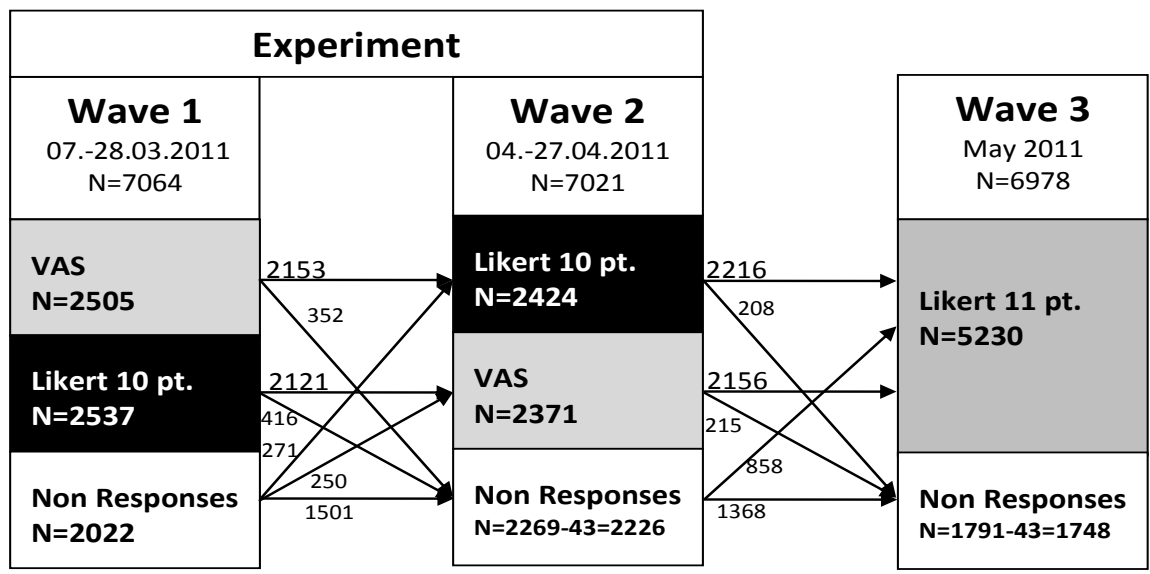

Figure 2: Screenshots of Happiness Questions

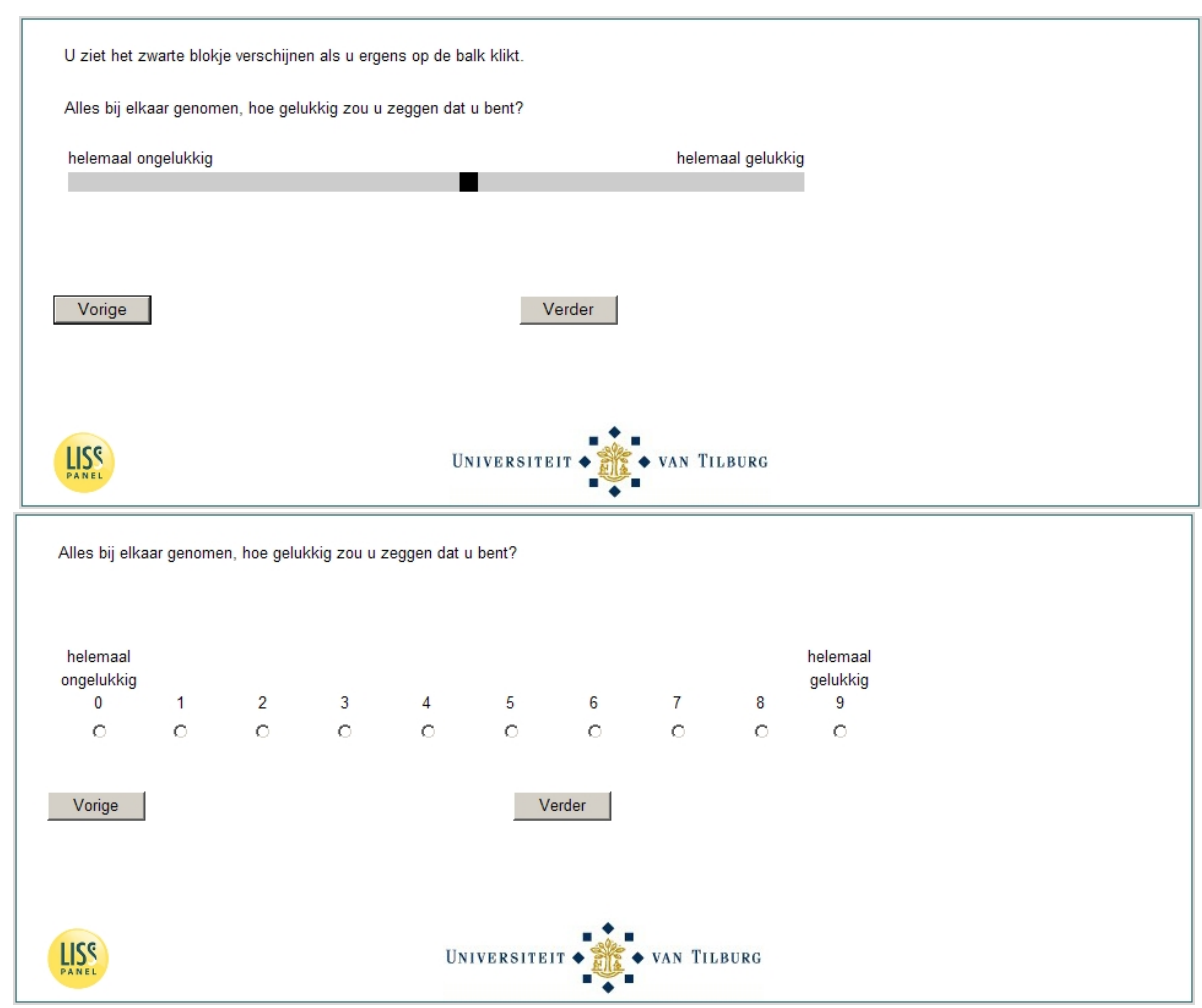


Figure 3: Question evaluation
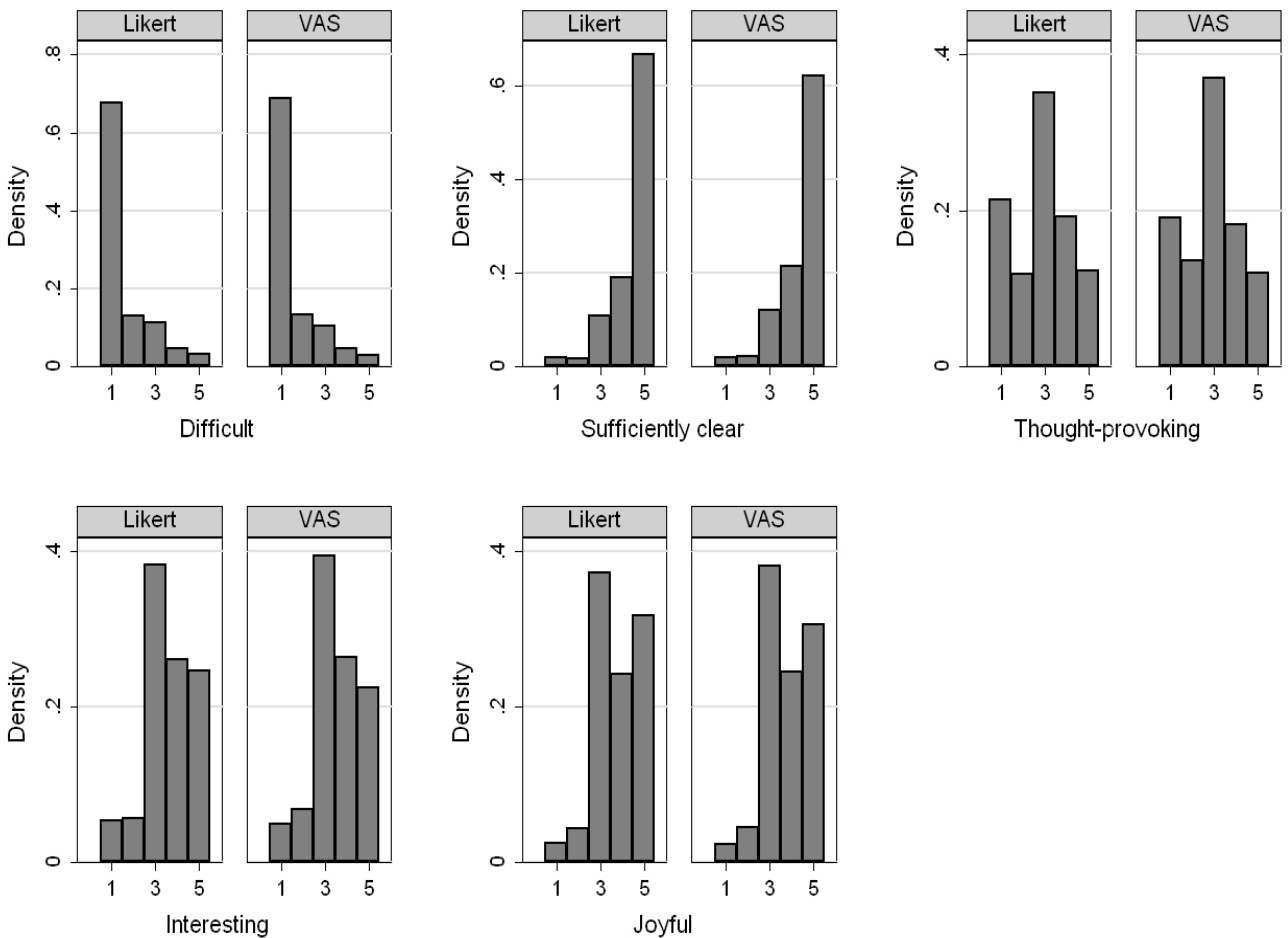

Note: 1 'certainly no' and 5 'certainly yes'

Figure 4: Happiness Densities - March and April Wave
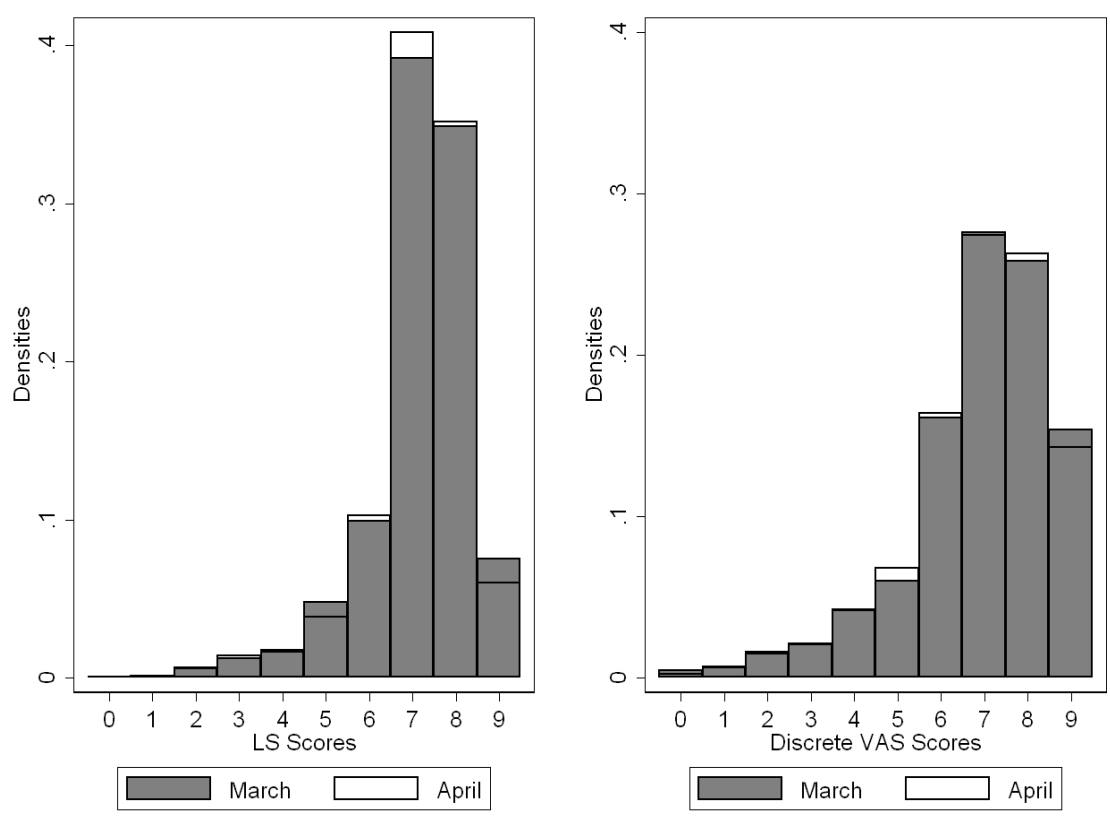
Figure 5: Happiness Densities - March Wave

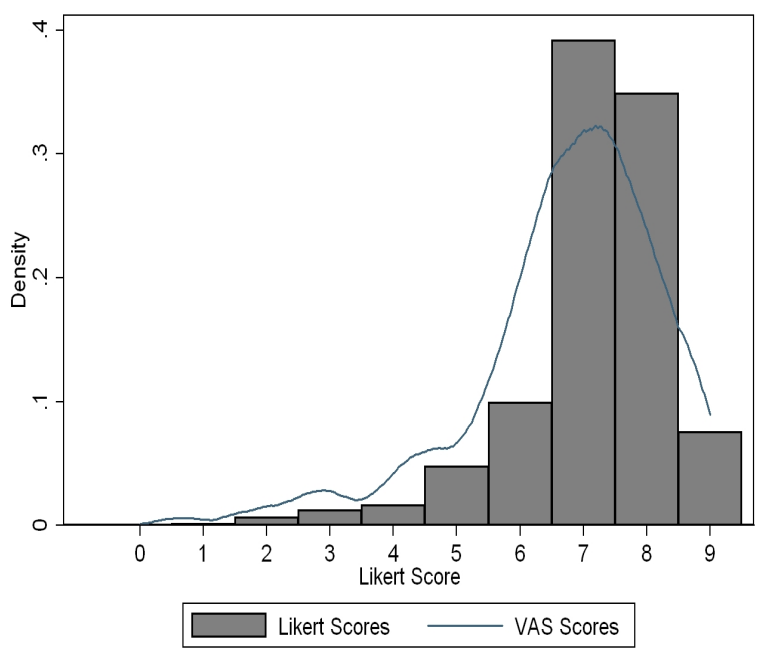

